\title{
Emergence of enterovirus D68 in Denmark, June 2014 to February 2015
}

S E Midgley (soi@ssi.dk)1, C B Christiansen², M W Poulsen¹, C H Hansen¹, T K Fischer ${ }^{1,3}$

1. Section for Virus Surveillance and Research, Department of Microbiological Diagnostics and Virology, Statens Serum Institut, Copenhagen, Denmark

2. Department of Clinical Microbiology, Rigshospitalet, Copenhagen, Denmark

3. Center for Global Health, Clinical Institute, Syddansk University, Odense, Denmark

Citation style for this article:

Midgley SE, Christiansen CB, Poulsen MW, Hansen CH, Fischer TK. Emergence of enterovirus D68 in Denmark, June 2014 to February 2015 . Euro Surveill. 2015;20(17):pii=21105. Available online: http://www.eurosurveillance.org/ViewArticle.aspx?Articleld=21105

Article submitted on 20 April 2015 / published on 30 April 2015

From June 2014 through February 2015, respiratory samples from 130 Danish patients were screened for enterovirus D68 (EV-D68). Fourteen EV-D68 cases were detected, of which 12 presented with respiratory symptoms, and eight had known underlying disease. The median age of EV-D68 cases was three years (interquartile range: $0-30$ years). Acute flaccid paralysis (AFP) was not detected although Danish EV-D68 strains showed $>98 \%$ nt identity with EV-D68-strains from AFP cases from the United States and France.

This study reports the burden and characteristics of enterovirus D68 (EV-D68) disease in Denmark from June 2014 through February 2015. A retro- and prospective EV-D68 surveillance study was implemented at the National Danish World Health Organization (WHO) Reference Laboratory for Poliovirus at Statens Serum Institut (SSI) Copenhagen, in September 2014 as a result of the extensive outbreak of severe respiratory disease caused by EV-D68 in the United States (US) [1] and Canada [2] that started in July 2014. Surveillance for EV-D68 in respiratory samples has continued in Denmark since then. A number of neurological cases associated with EV-D68 have also been reported [3-5], as well as a small number of likely EV-D68 associated fatalities [6].

\section{Laboratory investigation}

In the study, we included a total of 1,322 samples, predominantly of respiratory origin, but also cerebrospinal fluid and unspecified swabs from patients from general practitioners (GPs) (26\%) and hospital inpatients (74\%). Samples were submitted to SSI for diagnostic testing for respiratory viruses, and respiratory samples of both GP ( $2 \%$ ) and hospital origin (98\%) were submitted for EV genotyping as part of the national EV surveillance [7], between 1 June 2014 and 28 February 2015. Informed consent from patients was not required according to Danish legislation regarding use of samples collected for surveillance purposes. Human rhinovirus (HRV) ribonucleic acid (RNA) was detected using an in-house real-time RT (reverse transcriptase)-PCR assay, and EV RNA was detected using primers described previously [8], both assays targeting the 5 'non-translated region (NTR) and expected to detect all HRV and EV genotypes. A total of 130 samples representing 119 individuals tested positive for either HRV, EV, or HRV and EV. Of the 130 samples, 61 (47\%) were EV-positive only, 41 (31.5\%) were HRV positive only, and 28 (21.5\%) were both EV and HRV positive (Table 1). Nasopharyngeal secretion was the most commonly submitted sample material, followed by tracheal secretion.

Ninety-two samples were from children (range 0-15 years of age) and 38 samples were from adults (range 21-88 years of age). The sex distribution was slightly

\section{TABLE 1}

Clinical samples screened for enterovirus D68, Denmark, 1 June 2014 to 28 February $2015(n=130)$

\begin{tabular}{|l|c|c|c|c|}
\hline \multirow{2}{*}{ Sample material } & \multicolumn{3}{|c|}{ Diagnostic finding } & \multirow{2}{*}{ Total } \\
\cline { 2 - 5 } & EV & EV and HRV & HRV & \\
\hline BAL & 1 & 0 & 5 & 6 \\
\hline Biopsy ${ }^{\text {a }}$ & 4 & 0 & 0 & 4 \\
\hline CSF & 2 & 0 & 0 & 2 \\
\hline Expectorate & 2 & 2 & 0 & 4 \\
\hline Nasopharyngeal secretion & 28 & 13 & 11 & 52 \\
\hline Swab & 1 & 4 & 3 & 8 \\
\hline Tracheal secretion & 17 & 5 & 10 & 32 \\
\hline Unspecified & 6 & 4 & 12 & 22 \\
\hline Total & 61 & 28 & 41 & 130 \\
\hline
\end{tabular}

BAL: bronchoalveolar lavage; CSF: cerebrospinal fluid; EV: enterovirus; HRV: human rhinovirus.

a Biopsy materials included lung and lymph node tissue.

Swabs were taken from unspecified locations and tongue. 
TABLE 2

Enterovirus D68-positive cases Denmark, detected between September and November 2014 ( $\mathrm{n}=14$ )

\begin{tabular}{|c|c|c|c|c|c|c|}
\hline Case & Clinical information & Underlying disease & Age & Sampling date & Sample material & $\begin{array}{l}\text { Diagnostic } \\
\text { findings }\end{array}$ \\
\hline 1 & $\begin{array}{c}\text { Pneumonia and } \\
\text { respiratory failure lasting } \\
\text { four weeks }\end{array}$ & Pulmonary defect and asthma & 2 & 24 Sep 2014 & Tracheal secretion & $\begin{array}{c}\text { EV } \\
\text { and HRV-positive }\end{array}$ \\
\hline 2 & $\begin{array}{l}\text { Acute bronchitis, repeated } \\
\text { admissions during a three- } \\
\text { month period }\end{array}$ & $\begin{array}{l}\text { Pulmonary defect and/or } \\
\text { chronic lung disease }\end{array}$ & 0 & 30 Sep 2014 & Tracheal secretion & $\begin{array}{l}\text { EV- and HRV- } \\
\text { positive }\end{array}$ \\
\hline 3 & Cough and fever & Malignancy & 1 & 9 Oct 2014 & $\begin{array}{l}\text { Nasopharyngeal } \\
\text { secretion }\end{array}$ & EV-positive \\
\hline 4 & Pneumonia & $\begin{array}{l}\text { Pulmonary defect and/or } \\
\text { chronic lung disease }\end{array}$ & 7 & 13 Oct 2014 & $\begin{array}{l}\text { Nasopharyngeal } \\
\text { secretion }\end{array}$ & EV-positive \\
\hline 5 & Acute respiratory failure & $\begin{array}{l}\text { Cardiac disease and/or chronic } \\
\text { lung disease }\end{array}$ & 4 & 14 Oct 2014 & $\begin{array}{l}\text { Nasopharyngeal } \\
\text { secretion }\end{array}$ & $\begin{array}{l}\text { EV-and HRV } \\
\text { positive }\end{array}$ \\
\hline 6 & $\begin{array}{c}\text { Coughing and fever lasting } \\
\text { three weeks }\end{array}$ & $\begin{array}{l}\text { Cardiac disease and/or chronic } \\
\text { lung disease }\end{array}$ & 0 & 20 Oct 2014 & $\begin{array}{c}\text { Nasopharyngeal } \\
\text { secretion }\end{array}$ & EV-positive \\
\hline 7 & $\begin{array}{l}\text { Asthmatic wheezing } \\
\text { for seven days, not } \\
\text { responding to standard } \\
\text { inhalation treatment }\end{array}$ & None & 2 & 24 Oct 2014 & $\begin{array}{l}\text { Nasopharyngeal } \\
\text { secretion }\end{array}$ & EV-positive \\
\hline 8 & $\begin{array}{l}\text { Low grade }{ }^{\text {a }} \text { fever for four } \\
\text { days }\end{array}$ & None & 3 & 27 Oct 2014 & $\begin{array}{c}\text { Nasopharyngeal } \\
\text { secretion }\end{array}$ & $\begin{array}{l}\text { EV- and HRV- } \\
\text { positive }\end{array}$ \\
\hline 9 & $\begin{array}{c}\text { Acute onset, throat pain, } \\
\text { coughing, muscle pain, } \\
\text { fatigue, fever } 38-39^{\circ} \mathrm{C}, \\
\text { severe congestion and } \\
\text { runny nose, lasting eight } \\
\text { days }\end{array}$ & None & 61 & 3 Nov 2014 & Expectorate & $\begin{array}{l}\text { EV- and HRV- } \\
\text { positive }\end{array}$ \\
\hline 10 & $\begin{array}{l}\text { Mild pharyngitis for five } \\
\text { days }\end{array}$ & None & 30 & 4 Nov 2014 & Unspecified & $\begin{array}{l}\text { EV- and HRV- } \\
\text { positive }\end{array}$ \\
\hline 11 & $\begin{array}{c}\text { Cough and fever for one } \\
\text { week }\end{array}$ & None & 0 & 26 Nov 2014 & Tracheal secretion & $\begin{array}{c}\text { EV- and } \\
\text { HRV-positive }\end{array}$ \\
\hline 12 & $\begin{array}{l}\text { Cough and fever for two } \\
\text { weeks; acute breathing } \\
\text { difficulties resulting in } \\
\text { CPAP treatment upon } \\
\text { hospital admission (nine } \\
\text { days). }\end{array}$ & None & 68 & 26 Nov 2014 & Unspecified & $\begin{array}{l}\text { EV- and HRV- } \\
\text { positive }\end{array}$ \\
\hline 13 & $\begin{array}{l}\text { Cough, congestion and } \\
\text { fever lasting } 21 \text { days }\end{array}$ & Malignancy & 3 & 26 Nov 2014 & $\begin{array}{c}\text { Nasopharyngeal } \\
\text { secretion }\end{array}$ & EV-positive \\
\hline 14 & $\begin{array}{c}\text { Asthmatic cough and fever } \\
\text { for four weeks }\end{array}$ & Malignancy & 5 & 27 Nov 2014 & $\begin{array}{l}\text { Nasopharyngeal } \\
\text { secretion }\end{array}$ & EV-positive \\
\hline
\end{tabular}

CPAP: continuous positive airway pressure; EV: enterovirus; HRV: human rhinovirus.

a Fever $<38^{\circ} \mathrm{C}$.

skewed as 51/92 of children were male and 22/38 adults were female.

All samples that tested positive for EV and/or HRV RNA in the diagnostic test were screened with an EV-D68 specific real-time RT-PCR [9]. As part of the Danish enterovirus surveillance system all EV positive samples were further characterised at the National WHO Reference Laboratory for Poliovirus at SSI, using the routine genotyping assay which amplifies part of the VP2 or VP1 region $[10,11]$ followed by Sanger sequencing [7]. Fourteen patients were identified as EV-D68positive (Table 2 ).
Twelve of these cases were detected using the EVD68 specific real-time RT-PCR, two were detected by sequencing the amplicon from the VP2 PCR (data not shown). Eight were EV- and HRV-positive in the initial diagnostic test, the remaining six were EV-positive. All EV-D68 cases were detected between September and November 2014, which corresponds to the main peak of the EV season in Denmark 2014 (Figure 1, Table 2). Information on duration of illness was available for 10 patients, and patients with underlying conditions had a longer duration of illness (three weeks or longer, 
compared with four to 14 days for patients with no underlying condition).

All EV-D68-positive samples from 2014, as well as historical samples, were characterised using an assay specific for the VP1 region of EV-D68 [12] and included in the phylogenetic analysis.

All PCR amplicons were sequenced using the forward and reverse primers from the $\mathrm{VP}_{1}$ and $\mathrm{VP}_{2}$ assays on an $A B I 3500$ automated sequencer (Applied Biosystems). Sequences were assembled in BioNumerics v6.6 (Applied Maths BV) and genotyped using BLAST analysis in the genotyping database and on GenBank. Sequences were aligned with published EV-D68 sequences downloaded from GenBank using the SSE v1.1 software [13]. The most appropriate phylogenetic model for the data was found using the model test function in MEGA6 [14], and phylogenetic analysis was carried out using maximum likelihood with the Kimura 2 parameter algorithm, gamma distribution, invariable sites and 1,000 bootstrap replications, also in MEGA6. Sequences obtained in this study were submitted to GenBank, accession numbers KP729103-KP729109, and KR108018 - KR108026. All primers used in this study can be seen in Table 3 .

\section{Phylogenetic analyses}

All but two samples amplified successfully in the EV-D68 specific VP1 assay, producing sequences of around $800 \mathrm{nt}$. The two samples which could not be characterised using VP1 were the same two that failed to amplify in the real-time assay, and were confirmed to be EV-D68 by VP2 sequence analysis. Four historical EV-D68-positive samples were successfully amplified in the EV-D68 specific VP1 assay. BLAST analysis of the Danish VP1 sequences revealed that 6/12 of the Danish

\section{FIGURE 1}

Seasonal distribution of cases of enterovirus and enterovirus D68 infection, Denmark, 2014

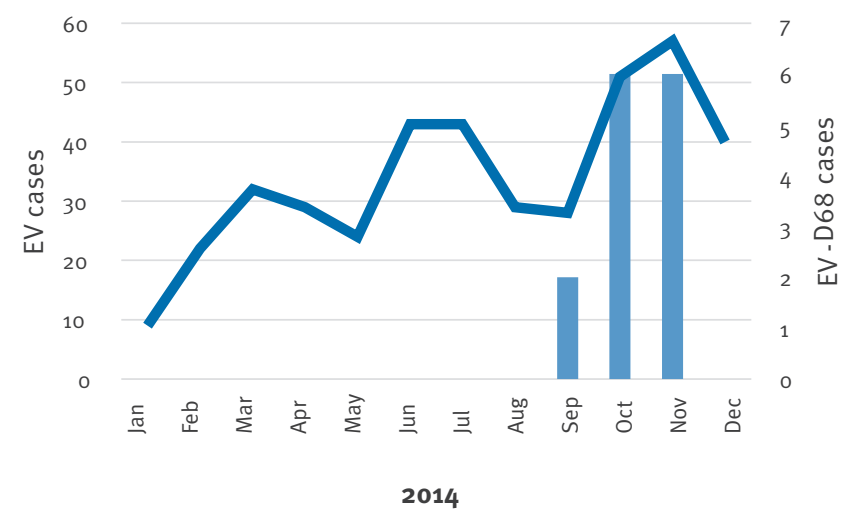

EV-D68 cases EV cases

EV: enterovirus.

Samples taken between January and May 2014 were not screened for the presence of enterovirus D68.
EV-D68 strains showed $>98 \%$ homology in $100 \%$ of the sequence (between 716 and 839 nt in length) with the US 2014 outbreak strains, and 2/12 strains showed>98\% homology with a EV-D68 strain from an acute flaccid paralysis (AFP) case in France case (LN626610). The remaining four Danish 2014 strains shared >98\% homology with other French 2014 EV-D68 strains. Phylogenetic analysis of the 12 EV-D68 VP1 sequences identified eight clusters containing Danish strains of EV-D68 (Figure 2). Eleven of the Danish strains from 2014 cluster within clade B as described by Tokarz et al., 2012 [12], one clusters within clade A. Strains from 2008, 2010, and 2013 cluster within clade A.

\section{Discussion}

EV-D68 which is a member of the large picornaviridae family of viruses, has primarily been associated with mild to severe respiratory infections $[15,16]$. Historically, EV-D68 was only sporadically detected worldwide during the usual EV seasonal epidemics, but since 2008 the EV-D68 has occasionally given rise to larger outbreaks globally $[15,17]$, although no previous outbreak has seen neither the same scale nor severity as the North American EV-D68 outbreak in 2014 [1]. Shortly after the North American outbreak was announced in July, EV-D68 cases were detected in Europe, and the European Centre for Disease Prevention and Control (ECDC) issued a rapid risk assessment on 26 September 2014 [18]. Denmark joined an initiative started by the European Society for Clinical Virology (ESCV) to investigate the prevalence of EV-D68 in the European region in a retro- and prospective study covering June through November 2014.

In Denmark, ca $10 \%$ of respiratory samples tested between June 2014 and February 2015 were positive for $\mathrm{EV}$ and/or HRV, and of these $11 \%$ were determined to be EV-D68 by a combination of $5^{\prime}$ NTR, VP1 and VP2 PCR and sequencing. This is a comparable detection rate to that described in other countries during the same time period [19]. No EV-D68 was detected in samples that were HRV-positive only, suggesting that the EV and HRV diagnostic result for EV-D68 cases is due to cross-reaction in the HRV assay. However, only $29.6 \%$ of double positive EV and HRV cases were associated with EV-D68. Other respiratory EV may also cross-react in an HRV assay in the 5'NTR, and, as a consequence, diagnostic laboratory reports from SSI for samples which are EV and HRV positive now contain a comment stating that this result may be due to infection with a virus detectable using both assays, rather than a double infection. The number of samples with this result has historically been small at SSI; should it continue to increase beyond the $10 \%$ rate identified in this study, the HRV assay may need to be revised.

Not all EV-D68 samples were detected using real-time and VP1 PCR, illustrating the difficulties in detecting and genotyping EVs in general due to the high level of diversity within this family of viruses. Danish strains 
TABLE 3

Primers used for the detection and amplification of enterovirus D68

\begin{tabular}{|c|c|c|c|c|}
\hline Assay & $\begin{array}{l}\text { Target } \\
\text { region }\end{array}$ & Forward primer ${ }^{\mathrm{a}}$ & Reverse primer $^{\mathrm{a}}$ & Probe \\
\hline EV diagnostic [8] & $5^{\prime}$ NTR & GGTGCGAAGAGTCTATTGAGC & CACCCAAAGTAGTCGGTTCC & FAM-CCGGCCCCTGAATG-MGB \\
\hline \multirow{2}{*}{$\begin{array}{l}\text { EV-D68 specific } \\
\text { diagnostic }\end{array}$} & \multirow{2}{*}{$5^{\prime} \mathrm{NTR}$} & \multirow{2}{*}{ TGTTCCCACGGTTGAAAACAA } & \multirow{2}{*}{ TGTCTAGCGTCTCATGGTTTTCAC } & FAM-TCCGCTATAGTACTTCG-MGB \\
\hline & & & & FAM-ACCGCTATAGTACTTCG-MGB \\
\hline \multirow{4}{*}{ Nasri [10] } & \multirow{4}{*}{$\mathrm{VP}_{2}$} & & TTPATDATYTCDTCICA & \multirow{4}{*}{ NA } \\
\hline & & GARGCITGYGGITAYAGYGA & IIDAIDATYIGRIGIGG & \\
\hline & & GGITGGTGGTGGAARYTICC & \multirow[t]{2}{*}{ TTDATCCAYTGRTGIGG } & \\
\hline & & GGITGGTAYTGGAARTTICC & & \\
\hline & & & & \\
\hline \multirow{6}{*}{ Nix [11] } & \multirow{6}{*}{ VP1 } & GCIATGYTIGGIACICAYRT & GTYTGCCA & \multirow{6}{*}{ NA } \\
\hline & & \multirow{5}{*}{ CCAGCACTGACAGCAGYNGARAYNGG } & GAYTGCCA & \\
\hline & & & CCRTCRTA & \\
\hline & & & RCTYTGCCA & \\
\hline & & & CICCIGGIGGIAYRWACAT & \\
\hline & & & TACTGGACCACCTGGNGGNAYRWACAT & \\
\hline \multirow{3}{*}{ Tokarz [12] } & & & & \\
\hline & \multirow[t]{2}{*}{$\mathrm{VP}_{1}$} & CCTTAATAGGGTTCATAGCAGC & CTGGGCCGGTGGTYACTA & \multirow[t]{2}{*}{ NA } \\
\hline & & ATGAGAGAYAGYCCTGACATTG & CATTGAGBGCATTTGGTGCT & \\
\hline
\end{tabular}

EV: enterovirus; NA: not applicable.

a Degenerate bases: I- inosine, B- C/G/T, D- A/G/T, N- A/C/G/T, R- A/G, Y- C/T, W-A/T.

were genetically very closely related to strains from AFP cases in the US and France, and AFP cases have also been described in Norway $[19,20]$. Strains from 2014 from countries other than Denmark also show a close genetic relationship to strains from AFP cases, suggesting host factors play an important role in the development of AFP as a result of EV-D68 infection. Underlying disease appears to increase the risk for severe infection, and therefore potentially also AFP. There is, however, no definite link between underlying disease and development of AFP, suggesting the involvement of other host factors. The level of viraemia may also contribute.

Following the detection of the first Danish EV-D68 cases during the fall of 2014, the National WHO Reference Laboratory for Poliovirus at SSI communicated these findings, alongside a description of the EV-D68 epidemic in the US, to all Danish clinicians including general practitioners and microbiologists with an appeal for vigilance regarding severe respiratory symptoms and AFP. Newsletters were posted on the National Clinical and Microbiology Societies websites and sent out using mailing lists, and an article was published in the weekly epidemiological Bulletin (EPI-NEWS) issued by the SSI [21]. Although Danish cases with EV-D68 and underlying conditions did experience severe respiratory symptoms, no cases of AFP were reported.
Acknowledgments

We are grateful to Ramona Trebbien at the Virus Surveillance and Research Section at Statens Serum Institut for useful scientific input to our manuscript and to Shila Mortensen and Ann Berith Pedersen for assisting with the routine diagnostic PCR at the Department of Microbiological Diagnostics and Virology at Statens Serum Institut. We also thank Dr. Martin Hulgaard at The Paediatric Department at Kolding hospital

Conflict of interest

None declared.

Authors' contributions

SEM: drafted the manuscript and conducted the phylogenetic analyses.

CBC: provided respiratory samples for enterovirus characterisation and collected clinical information about EV-D68 cases.

MWP: conducted the laboratory characterisation of enteroviruses presented in this paper.

$\mathrm{CHH}$ : critical review of the literature regarding the 2014 outbreak.

TKF: conceptualised the study and has participated in writing of the manuscript together with SEM. 


\section{FIGURE 2}

Phylogenetic analysis of enterovirus D68 VP1 sequences

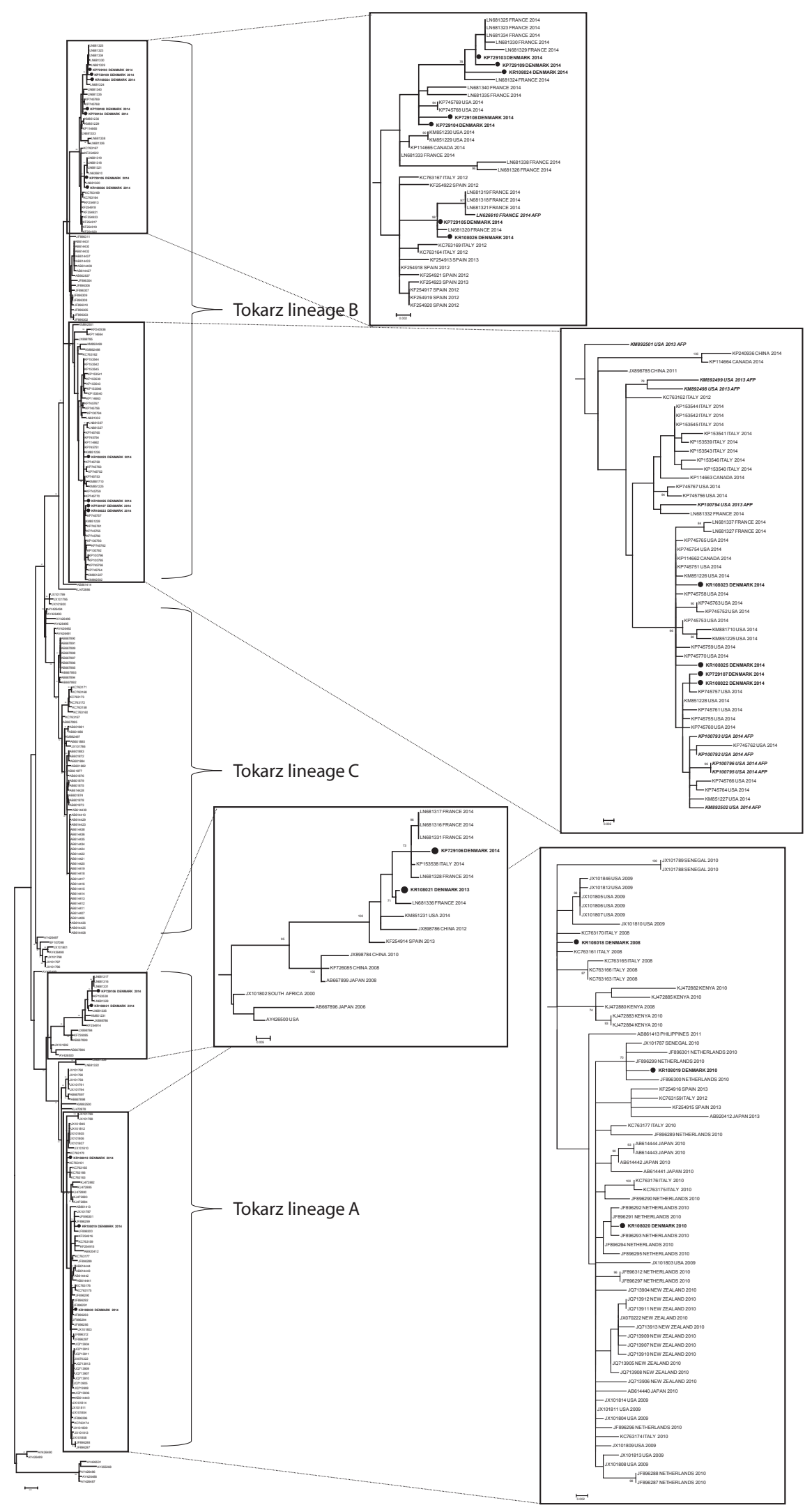

The phylogenetic tree was constructed by maximum likelihood, with the Kimura 2-parameter algorithm, with gamma distribution, invariable sites and 1,000 bootstrap replicates, using MEGA6. Only bootstrap values $>70 \%$ are indicated. Branch lengths are drawn to the indicated scale, proportion of nt substitutions per site. Sequences were $731 \mathrm{nt}$ in length. Reference sequences were downloaded from GenBank; all complete or near complete genomes $(n=50$, downloaded 14 Apr 2015), as well as partial VP1 sequences $>700$ nt in length with complete overlap with the sequences from this study $(n=232$, downloaded 14 Apr 2015) were included, resulting in a dataset of 294 sequences. GenBank reference sequences and sequences from this study are identified by their accession numbers. Country of origin and detection year is specified after the sequence ID (where available) for references and study samples within defined clusters. Four EV-D68 sequences from the Danish genotyping database, identified between 2008 and 2013, were also included in the analysis. Sequences from this study are identified with filled circles and bold text. Reference sequences from known acute flaccid paralysis cases are identified with bold italics. 


\section{References}

1. Midgley CM, Jackson MA, Selvarangan R, Turabelidze G, Obringer $E$, Johnson D, et al. Severe respiratory illness associated with enterovirus D68 - Missouri and Illinois, 2014. MMWR Morb Mortal Wkly Rep. 2014;63(36):798-9. PMID:25211545

2. National Collaborating Centre for Infectious Diseases (NCCID) Disease debrief: EV-D68. Winnipeg, Manitoba: NCCID.

[Accessed 21 Nov 2014]. Available from: http://www.nccid.ca/ disease-debrief-ev-d68\#Q1.

3. Pastula DM, Aliabadi N, Haynes AK, Messacar K, Schreiner T, Maloney J, et al.; Centers for Disease Control and Prevention (CDC). Acute neurologic illness of unknown etiology in children - Colorado, August-September 2014. MMWR Morb Mortal Wkly Rep. 2014;63(40):901-2. PMID:25299607

4. British Columbia Centre for Disease Control. Emerging respiratory virus bulletin: MERS-CoV, Influenza $\mathrm{A}\left(\mathrm{H}_{7} \mathrm{~N}_{9}\right)$ and $\mathrm{A}\left(\mathrm{H}_{3} \mathrm{~N}_{2}\right) \mathrm{v}$, Enterovirus D68. British Columbia: Centre for Disease Control. 4 Oct 2014. Available from: http:// www.bccdc.ca/NR/rdonlyres/88FD3DD4-BEBo-4F29-93Co6093A7AFBD4B/o/Full_ERVUpdate20141004.pdf

5. Lang M, Mirand A, Savy N, Henquell C, Maridet S, Perignon $\mathrm{R}$, et al. Acute flaccid paralysis following enterovirus D68 associated pneumonia, France, 2014. Euro Surveill. 2014;19(44):20952. http://dx.doi.org/10.2807/1560-7917. ES2014.19.44.20952 PMID:25394254

6. Centers for Disease Control and Prevention. Non-Polio Enterovirus: Enterovirus D68. Atlanta: National Center for Immunization and Respiratory Diseases (NCIRD), Division of Viral Diseases, Centers for Disease Control and Prevention. Updated 23 Mar 2015. Available from: http://www.cdc.gov/ non-polio-enterovirus/about/ev-d68.html

7. Fischer TK, Nielsen AY, Sydenham TV, Andersen PH, Andersen $\mathrm{B}$, Midgley SE. Emergence of enterovirus 71 C4a in Denmark, 2009 to 2013. Euro Surveill. 2014;19(38):20911. http://dx.doi. org/10.2807/1560-7917.ES2014.19.38.20911 PMID:25306878

8. Nielsen AC, Böttiger B, Midgley SE, Nielsen LP. A novel enterovirus and parechovirus multiplex one-step realtime PCR-validation and clinical experience. J Virol Methods. 2013;193(2):359-63. http://dx.doi.org/10.1016/j. jviromet.2013.06.038 PMID:23845901

9. Poelman R, Schölvinck EH, Borger R, Niesters HGM, van Leer-Buter C. The emergence of enterovirus D68 in a Dutch University Medical Center and the necessity for routinely screening for respiratory viruses. J Clin Virol. 2015;62:1-5. http://dx.doi.org/10.1016/j.jcv.2014.11.011 PMID:25542461

10. Nasri D, Bouslama L, Omar S, Saoudin H, Bourlet T, Aouni M, et al. Typing of human enterovirus by partial sequencing of VP2. J Clin Microbiol. 2007;45(8):2370-9. http://dx.doi.org/10.1128/ JCM.00093-07 PMID:17537940

11. Nix WA, Oberste MS, Pallansch MA. Sensitive, seminested PCR amplification of $\mathrm{VP}_{1}$ sequences for direct identification of all enterovirus serotypes from original clinical specimens. J Clin Microbiol. 2006;44(8):2698-704. http://dx.doi.org/10.1128/ JCM.00542-06 PMID:16891480

12. Tokarz R, Firth C, Madhi SA, Howie SR, Wu W, Sall AA, et al. Worldwide emergence of multiple clades of enterovirus 68 . Gen Virol. 2012;93(Pt 9):1952-8. http://dx.doi.org/10.1099/ vir.0.043935-0 PMID:22694903

13. Simmonds P. SSE: a nucleotide and amino acid sequence analysis platform. BMC Res Notes. 2012;5(1):50. http://dx.doi. org/10.1186/1756-0500-5-50 PMID:22264264

14. Tamura K, Stecher G, Peterson D, Filipski A, Kumar S. MEGA6: Molecular Evolutionary Genetics Analysis version 6.o. Mol Biol Evol. 2013;30(12):2725-9. http://dx.doi.org/10.1093/molbev/ mst197 PMID:24132122

15. Meijer A, van der Sanden S, Snijders BE, Jaramillo-Gutierrez $G$, Bont L, van der Ent CK, et al. Emergence and epidemic occurrence of enterovirus 68 respiratory infections in The Netherlands in 2010. Virology. 2012;423(1):49-57. http:// dx.doi.org/10.1016/j.virol.2011.11.021 PMID:22177700

16. Renois F, Bouin A, Andreoletti L. Enterovirus 68 in pediatric patients hospitalized for acute airway diseases. J Clin Microbiol. 2013;51(2):640-3. http://dx.doi.org/10.1128/ JCM.02640-12 PMID:23224095

17. Meijer A, Benschop KS, Donker GA, van der Avoort HG Continued seasonal circulation of enterovirus D68 in the Netherlands, 2011-2014. Euro Surveill. 2014;19(42):20935. http://dx.doi.org/10.2807/1560-7917.ES2014.19.42.20935 PMID:25358039

18. Eurosurveillance editorial team. ECDC's latest publications. Euro Surveill. 2014;19(39):20915. Available from: http://www. eurosurveillance.org/ViewArticle.aspx?Articleld=20915

19. Bragstad K, Jakobsen K, Rojahn AE, Skram MK, Vainio K, Holberg-Petersen $M$, et al. High frequency of enterovirus D68 in children hospitalised with respiratory illness in Norway, autumn 2014. Influenza Other Respi Viruses. 2015;9(2):59-63.

20. Pfeiffer HC, Bragstad K, Skram MK, Dahl H, Knudsen PK, Chawla MS, et al. Two cases of acute severe flaccid myelitis associated with enterovirus D68 infection in children, Norway, autumn 2014. Euro Surveill. 2015;20(10):21062. http://dx.doi. org/10.2807/1560-7917.ES2015.20.10.21062 PMID:25788251

21. Fischer TK, Midgley SE, Poulsen MW, Andersen B, Christiansen $\mathrm{CB}$, Andersen PH. Outbreak of enterovirus D68 in children in USA and Canada, and circulation in Denmark. EPI-NYT 2014;49. Available from: http://www.ssi.dk/pdf.ashx?title=No49---2014---EPI-NEWS\&url=http\%3a\%2f\%2fwww. ssi.dk\%2fEnglish\%2fNews\%2fEPINEWS\%2f $2014 \% 2 f$ o $_{2}+49+-+2014$.aspx\%3fpdf\%3d1 